\title{
Determination of Pesticide Residues by GC-MS in Commercialized Mint Samples
}

Mohammed Jbilou1 ${ }^{1}$ Khalid Laarej ${ }^{1}$, Rachid Alami ${ }^{1 *}$, Abdelaziz Bouklouze $^{2}$, Yahia Cherrah $^{2}$, Adil El Yadini $^{3}$ and My Elabbes Faouzi ${ }^{4}$

${ }^{1}$ Research Laboratory and Medical Analysis of the Royal Gendarmerie, Rabat, Morocco

${ }^{2}$ Research Team - Pharmaceutical Pharmacology and Toxicology Laboratory, Faculty of Medicine and Pharmacy, Mohammed V University in Rabat, Morocco

${ }^{3}$ Laboratory of Spectroscopy, Molecular Modelisation, Material and Environment (LS3ME), Faculty of Sciences, University Med V-Agdal, Avenue Ibn Battouta, BP 1014,

Agdal, Rabat, Morocco

${ }^{4}$ Pharmacocinetic Team Laboratory of Pharmacology and Toxicology, Faculty of Medicine and Pharmacy, Mohammed V University in Rabat, Morocco

\begin{abstract}
The sale of fresh mint in Morocco is not strictly controlled as for that which is intended for export to the European Union, which increases the risks of the contamination of mint tea consumers and constitutes a problem of public health. The method of dosing pesticides in fresh mint by GC-MS that we have developed and validated allowed us to high light contamination by pesticide residues (carbofuran, bifenthrin, chlopyriphos methyl and Fenpropathrin) in samples of mint fresh from sampled sale and temara, this contamination exceeds the MRLs. Regular control of the sale of fresh mint should be practiced to prevent repetitive contamination of local consumers by pesticide residues.
\end{abstract}

\section{Keywords: Pesticides; Mint; Dosing; GC-MS}

\section{Introduction}

Spearmint or mint, Mentha spicata L cv. viridis [1] or Mentha viridis $\mathrm{L}$ [2], is a perennial of the family Limiaceae. In Morocco, spearmint is widely used with tea which is a national beverage and has been a medicinal plant for decades [3]. Like other vegetal, spearmint has phytosanitary problems due to pests (aphids, leafhoppers, moths, white flies, etc.) [4]. To control these bio-aggressors, which often generate significant losses, farmers treat their fields with synthetic pesticides; against fungal diseases, fungicides such as bitertanol, boscalid, triadimenol, etc., whereas against pests it is mainly treated with cypermethrin, permethrin and endosulfan [5,6]. In Morocco, no synthetic pesticides have been registered on mint cultivation $[7,8]$. However, if the use of pesticides has been considered for years as the most cost-effective means of control, the profit margin is considerably reduced by subtracting the costs of their undesirable effects on the environment and human health [9]. Pesticides all have varying degrees of potential for toxicity and can unfortunately be toxic to non-target organisms, including humans [10]. By their serious side effects on human health and the environment [11]; Consumers, users or those who are generally infected may face health risks such as suppression of the immune system, impairment of intellectual capacity, hormonal disruption, cancer, etc. [12] According to the World Health Organization, the annual number of pesticide poisonings is about 5 million, children, infants, and the elderly are the most sensitive. Male nutrition and dehydration increase susceptibility to pesticides [13]. It is the areas with high agricultural activity that are most exposed to the risks of pesticides [14]. In Morocco almost 7\% of poisoning is of chemical origin, most of which is associated with the contamination of food by pesticides [15]. Exposure to pesticides can be through the respiratory, dermal and oral routes, the risk of which generally increases with the dose that does not necessarily improve the efficacy of the treatment [10]. Derived metabolites may also have a very disturbing toxicological profile. Their quantities and that of the parent molecule in or on the consumable parts of the plant at harvest depend on the nature of the pesticide, the climate, the plant being treated, the conditions of use, the formulation and the time to harvest (DAR) [16]. Moroccan fresh mint exported to the European Union (EU) is experiencing exceedances of the maximum residue limits (MRL) set by the latter $[17,18]$, while several local sales outlets are not controlled by lack of effective methods of pesticide residues in Moroccan fresh mint, from which the primary objective of this study is to develop and validate a new method for the determination of pesticide residues in mint by GC-MS and to apply it to mint samples marketed locally.

\section{Materials and Methods}

\section{Instrumentation}

The gas chromatographic system coupled to mass spectrometry is PerkinElmer GC-MS Clarus 600/560DMS equipped with an automatic injector. The system is driven by a software Turbo Mass Software (Microsoft Windows XP SP2). The stationary phase is a Supelco column (L $30 \mathrm{~m} \times$ ID $0.25 \mathrm{X}$ DF 0.25 ) of Elite-5MS phase, the carrier gas is helium at a flow rate of $0.8 \mathrm{~mL} / \mathrm{min}$. The oven was programmed from $90^{\circ} \mathrm{C}$ up to $230^{\circ} \mathrm{C}$ at a gradient of $15^{\circ} \mathrm{C}$ per min and then at $5^{\circ} \mathrm{C}$ per min up to $290^{\circ} \mathrm{C}$ with prior heating of the transfer line to $300^{\circ} \mathrm{C}$ and the ionization source at $250^{\circ} \mathrm{C}$. The automatic injection is in splitless mode $\left(50 / 1\right.$ to $\left.250^{\circ} \mathrm{C}\right)$. Ionization is caused by an electronic impact (IE).

\section{Reagents and chemicals}

Pesticide standards that have been used in the calibration range are LGC Standards.

- Acetonitrile, Toluene and Acetic acid.

- SPEXQuE QUECHERS KITS (Citrate Bufer Extraction Tubes).

- ULTRA QuECH (QUEC-208).

\section{Calibration range}

Preparation of the calibration range $(0.02 \mathrm{ppm}, 0.05 \mathrm{ppm}, 0.1 \mathrm{ppm}$, $0.2 \mathrm{ppm}$ and $0.5 \mathrm{ppm}$ ) was made from the stock solution of a mixture of

*Corresponding author: Rachid Alami, Research Laboratory and Medical Analysis of the Royal Gendarmerie, Rabat, Morocco, Tel: 21237272750; E-mail: alami.rachid89@yahoo.fr

Received May 03, 2018; Accepted May 25, 2018; Published May 31, 2018

Citation: Jbilou M, Laarej K, Alami R, Bouklouze A, Cherrah Y, et al. (2018) Determination of Pesticide Residues by GC-MS in Commercialized Mint Samples. J Environ Anal Toxicol 8: 572. doi: 10.4172/2161-0525.1000572

Copyright: @ $2018 \mathrm{Jbilou} \mathrm{M}$, et al. This is an open-access article distributed under the terms of the Creative Commons Attribution License, which permits unrestricted use, distribution, and reproduction in any medium, provided the original author and source are credited. 
Citation: Jbilou M, Laarej K, Alami R, Bouklouze A, Cherrah Y, et al. (2018) Determination of Pesticide Residues by GC-MS in Commercialized Mint Samples. J Environ Anal Toxicol 8: 572. doi: 10.4172/2161-0525.1000572

Page 2 of 7

18 pesticides (Aminocarb, Ethoprophos, Carbofuran, Chlorpropham, Chlorbufam, Methyl Acibenzolar, Methyl Chlorpyriphos, Fenpropidin, Diethiofencarb, Cyprodinil, ßendosulfan, Clodinafopropargyl, Buprofizin, Fenpropatrin, Fenarimol, Permetrin, Fenbuconazol and Boscalid) at $1 \mathrm{ppm}$ by successive dilutions. The sulfotep was used as an internal standard at $0.1 \mathrm{ppm}$.

\section{Collection and origin of samples of mint}

The samples of mint are brought from different sales outlets in the region of Rabat sale.

\section{Extraction by the method of QuECHERS}

Extraction: Transfer 5-10 g of the mint sample homogenate into a $50 \mathrm{~mL}$ conical tube, add $10 \mathrm{~mL}$ of the acetinitrile solution containing $1 \%$ acetic acid, $100 \mu \mathrm{L}$ of the internal standard and mix with the SPEXQuE Acetate Tube container (AOAC-ACE-50 mL). Vortex for 1 $\mathrm{min}$ and centrifuge at $3000 \mathrm{~g}$ for $5 \mathrm{~min}$.

Purification: Transfer $6 \mathrm{ml}$ of the organic phase into SPEXQuE PSA Tube (EN-PSA-15 mL) or $1 \mathrm{~mL}$ into SPEXQuE PSA Tube, $2 \mathrm{~mL}$ (ULTRA QuECH-QUEC-208). Vortex for $1 \mathrm{~min}$ and centrifuge at 3000 rpm for $5 \mathrm{~min}$. Fill a glass tube with $1 \mathrm{~mL}$ of the extract and evaporate to dryness under a stream of nitrogen. Resume the dry extract with $100 \mu \mathrm{l}$ of toluene and vortex for $1 \mathrm{~min}$. Transfer the extract into the injection vial and inject $3 \mu \mathrm{l}$ in splitless mode (Table 1).

\section{Results and Discussion}

\section{Development of the method of dosage}

After analysis, the chromatogram showing the peaks of the pesticides that make up the mixture was recorded in Figure 1 and the numerical results, Standard concentration (Cc), Retention time (TR), Concentration found (CT) and Yield (R) have been represented in Table 2. The electron impact molecular fragmentation of the mixing pesticides gave characteristic mass spectra for each product, some examples are shown in Figure 2. The most abundant mass peaks were selected for the development and validation of the assay method (Figure 3).

\section{Validation of the method of determination}

The criteria to be evaluated during the validation of this analytical method are; selectivity, linearity, fidelity, limits of quantification (LOQ) and inter-sample contamination.

Selectivity: The blank extract from the extraction of a sample of organic mint showed no signal at the retention times of different pesticides in the mixture (Figure 4).

Linearity: Over a dosing interval consisting of 5 concentration levels (0.02 ppm, $0.05 \mathrm{ppm}, 0.1 \mathrm{ppm}, 0.2 \mathrm{ppm}$ and $0.5 \mathrm{ppm}$ ), each concentration was repeated 3 times. The equation of the calibration line $(\mathrm{Y}=\mathrm{ax}+\mathrm{b})$ for each pesticide was calculated by the least squares method across the range (Figure 5) with satisfactory R2 repeat coefficients (Table 2).

Repeatability: The repeatability of this method was studied at $0.1 \mathrm{ppm}$, this concentration was repeated 5 times. The coefficients of variation $(\mathrm{CVr})$ calculated are less than $15 \%$ for all the pesticides in the mixture (Table 3).

Reproducibility: Reproducibility was performed on three independent series. The coefficients of variation (CVR) calculated are less than $15 \%$ for all the pesticides in the mixture (Table 3 ).
Quantation limit (LOQ): 5 samples of mint at $0.02 \mathrm{ppm}$ of pesticides were analyzed under conditions of fidelity. The results gave satisfactory CV\% coefficients of variation (Table 3).

Inter sample contamination: The injection of extracts of the organic mint just after the injection of mint extracts at $0.5 \mathrm{ppm}$ under conditions of fidelity showed no inter-sample contamination for all the pesticides in the mixture. The $\mathrm{CV} \%$ of the validation criteria are all less than $15 \%$ which confirms that this method is valid and we can apply it on mint samples that we have made (Table 1).

\section{Determination of pesticide residues in commercial mint samples}

The application of the method of determination of pesticide residues in mint by GC-MS that we validated on mint samples marketed showed that among the 16 samples analyzed we found pesticide residues in 3 samples (MST4, MSJ11 and MTM14), see Figure 5 and Table 4. The persistence of pesticide residues (permethrin, carbufuran, chlorpyrifos methyl and fenpropathrin) in the mint samples marketed at Sale and Temara is only the result of non-compliance with the preharvest intervals (PHI) for each pesticide (Table 4) and misuse of these pesticides during treatment by failure to follow the instructions for each product [19].

\section{Conclusion}

We validated a method for the determination of pesticide residues by GC-MS in mint. This method allowed us to evaluate the contamination of some samples of mint marketed locally. The results show the presence of pesticide residues in some samples at concentrations above the MRLs. This study will have to be extended to other regions to take the necessary measures to preserve the health of consumers.

\begin{tabular}{|c|c|c|c|}
\hline Mints Code & Origine & Amount & Nature \\
\hline MST1 & Salé tabrékte & $115 \mathrm{~g}$ & Fresh mint \\
\hline MST2 & Salé tabrékte & $103 \mathrm{~g}$ & Fresh mint \\
\hline MST3 & Salé tabrékte & $111 \mathrm{~g}$ & Fresh mint \\
\hline MST4 & Salé tabrékte & $110 \mathrm{~g}$ & Fresh mint \\
\hline MST5 & Salé tabrékte & $102 \mathrm{~g}$ & Fresh mint \\
\hline MSK6 & Salé hay karima & $113 \mathrm{~g}$ & Fresh mint \\
\hline MSJ7 & Salé eljadida & $117 \mathrm{~g}$ & Fresh mint \\
\hline MSJ8 & Salé eljadida & $111 \mathrm{~g}$ & Fresh mint \\
\hline MSJ9 & Salé eljadida & $119 \mathrm{~g}$ & Fresh mint \\
\hline MSJ10 & Salé eljadida & $122 \mathrm{~g}$ & Fresh mint \\
\hline MSJ11 & Salé eljadida & $131 \mathrm{~g}$ & Fresh mint \\
\hline MRA12 & Rabat agdal & $105 \mathrm{~g}$ & Fresh mint \\
\hline MTG13 & Témara guiche loudaya & $110 \mathrm{~g}$ & Fresh mint \\
\hline MTM14 & Témara elmassira & $111 \mathrm{~g}$ & Fresh mint \\
\hline MTC15 & Témara centre & $120 \mathrm{~g}$ & Fresh mint \\
\hline MTN16 & Témara hay enahda & $118 \mathrm{~g}$ & Fresh mint \\
\hline
\end{tabular}

Table 1: Origins of mint samples. 
Citation: Jbilou M, Laarej K, Alami R, Bouklouze A, Cherrah Y, et al. (2018) Determination of Pesticide Residues by GC-MS in Commercialized Mint Samples. J Environ Anal Toxicol 8: 572. doi: 10.4172/2161-0525.1000572

Page 3 of 7

\begin{tabular}{|c|c|c|c|c|c|c|}
\hline Pesticides & $C^{c}(p p m)$ & TR (min) & Masses pics $(\mathrm{m} / \mathrm{z})$ & Pics Qt $(m / z)$ & CT (ppm) & R (\%) \\
\hline Carbofuran & 0.1 & 5.96 & $164,149,122$ & 164 & 0.07 & 70 \\
\hline Aminocarb & 0.1 & 6.34 & $151,150,136$ & 151 & 0.06 & 60 \\
\hline Ethoprophos & 0.1 & 8.59 & $158,43,97$ & 158 & 0.08 & 80 \\
\hline Chlorpropham & 0.1 & 8.77 & $127,43,213$ & 127 & 0.07 & 70 \\
\hline Chlorbufam & 0.1 & 9.45 & $53,127,223$ & 53 & 0.07 & 70 \\
\hline Chlorpyriphos méthyle & 0.1 & 10. 52 & $125,286,79$ & 125 & 0.10 & 100 \\
\hline Acibenzolar méthyle & 0.1 & 10.65 & $63,182,107$ & 63 & 0.09 & 90 \\
\hline Fenpropidin & 0.1 & 10.78 & $98,99,55$ & 98 & 0.08 & 80 \\
\hline Diethiofencarb & 0.1 & 11.16 & $43,124,225$ & 124 & 0.09 & 90 \\
\hline Cyprodinil & 0.1 & 11.67 & $224,225,77$ & 224 & 0.08 & 80 \\
\hline$\beta$ endosulfan & 0.1 & 12.61 & $207,170,69$ & 207 & 0.06 & 60 \\
\hline Clodinafopropargyl & 0.1 & 13.09 & $238,266,130$ & 238 & 0.08 & 80 \\
\hline Buprofizin & 0.1 & 13.13 & $105,106,57$ & 105 & 0.09 & 90 \\
\hline Fenpropatrin & 0.1 & 16.24 & $97,55,181$ & 97 & 0.09 & 90 \\
\hline Fenarimol & 0.1 & 17.87 & $139,107,219$ & 139 & 0.08 & 80 \\
\hline Permethrin & 0.1 & 18.76 & $183,91,77$ & 183 & 0.08 & 80 \\
\hline Fenbuconazol & 0.1 & 19.75 & $129,198,125$ & 129 & 0.09 & 90 \\
\hline Boscalid & 0.1 & 20.43 & $140,112,142$ & 140 & 0.08 & 80 \\
\hline \multicolumn{6}{|c|}{ R Moy (\%) } & 75.78 \\
\hline
\end{tabular}

Table 2: Analytical Parameters of Mixture Pesticides.

\begin{tabular}{|c|c|c|c|c|c|c|}
\hline Pesticides & TR (min) & $\mathbf{R}$ & $\mathrm{LOQ}(\mu \mathrm{g} / \mathrm{ml})$ & $\mathrm{CV} \%$ & $\mathrm{CVr} \%$ & CVR\% \\
\hline Carbofuran & 5.96 & 0.996 & 0.02 & 5.70 & 3.21 & 4.99 \\
\hline Aminocarb & 6.34 & 0.993 & 0.02 & 6.57 & 0.7 & 3.21 \\
\hline Ethoprophos & 8.59 & 0.938 & 0.02 & 6.37 & 9.91 & 6.30 \\
\hline Chlorpropham & 8.77 & 0.984 & 0.02 & 3.99 & 0.53 & 1.85 \\
\hline Chlorbufam & 9.45 & 0.992 & 0.02 & 1.53 & 0.42 & 4.47 \\
\hline Acibenzolar méthyle & 10.65 & 0.998 & 0.02 & 2.91 & 0.54 & 4.02 \\
\hline Chlorpyriphos méthyle & 10.52 & 0.998 & 0.02 & 3.41 & 1.24 & 5.06 \\
\hline Fenpropidin & 10.78 & 0.998 & 0.02 & 3.24 & 1.14 & 5.43 \\
\hline Diethiofencarb & 11.16 & 0.999 & 0.02 & 3.04 & 0.92 & 4.64 \\
\hline Cyprodinil & 11.67 & 0.998 & 0.02 & 4.08 & 1.63 & 4.23 \\
\hline$\beta$ endosulfan & 12.61 & 0.977 & 0.02 & 5.00 & 2.97 & 6.17 \\
\hline Clodinafopropargyl & 13.09 & 0.998 & 0.02 & 4.98 & 2.97 & 4.56 \\
\hline Buprofizin & 13.13 & 0.999 & 0.02 & 2.24 & 0.88 & 3.49 \\
\hline Fenpropatrin & 16.25 & 0.999 & 0.02 & 2.99 & 0.43 & 5.02 \\
\hline Fenarimol & 17.87 & 0.998 & 0.02 & 7.22 & 0.44 & 6.43 \\
\hline Permethrin & 18.76 & 0.998 & 0.02 & 6.28 & 2.45 & 5.25 \\
\hline Fenbuconazol & 19.75 & 0.995 & 0.02 & 4.13 & 3.84 & 6.17 \\
\hline Boscalid & 20.43 & 0.998 & 0.02 & 4.95 & 2.55 & 5.29 \\
\hline
\end{tabular}

Table 3: Results of Validation of the Method for Determination of Pesticide Residues in Mint by GC-MS.

\begin{tabular}{|c|c|c|c|c|}
\hline Mint Code & Pesticides detected $(\mathrm{mg} / \mathrm{kg})$ & LMR UE (mg/kg) & DAR (days) & Interpretation \\
\hline MST1 & Negative & - & - & - \\
\hline MST2 & Negative & - & - & - \\
\hline MST3 & Negative & - & - & - \\
\hline MST4 & Permithrin (0.35) & 0.2 & 25 & >LMR UE \\
\hline MST5 & Negative & - & - & - \\
\hline MSK6 & Negative & - & - & - \\
\hline MSJ7 & Negative & - & - & - \\
\hline MSJ8 & Negative & - & - & - \\
\hline MSJ9 & Negative & - & - & - \\
\hline MSJ10 & Negative & - & - & - \\
\hline MSJ11 & Carbofuran (0.28) & ND & ND & - \\
\hline MRA12 & Negative & - & - & - \\
\hline MTG13 & Negative & - & - & - \\
\hline MTM14 & Chlorpyriphos méthyle (0.12) & 0.05 & 30 & > LMR UE \\
\hline MTM14 & Fenpropathrin (0.11) & ND & ND & - \\
\hline MTC15 & Negative & - & - & - \\
\hline MTN16 & Negative & - & - & - \\
\hline
\end{tabular}

Table 4: Results of Pesticide Residues in Mint Samples by GC-MS. 
Citation: Jbilou M, Laarej K, Alami R, Bouklouze A, Cherrah Y, et al. (2018) Determination of Pesticide Residues by GC-MS in Commercialized Mint Samples. J Environ Anal Toxicol 8: 572. doi: 10.4172/2161-0525.1000572

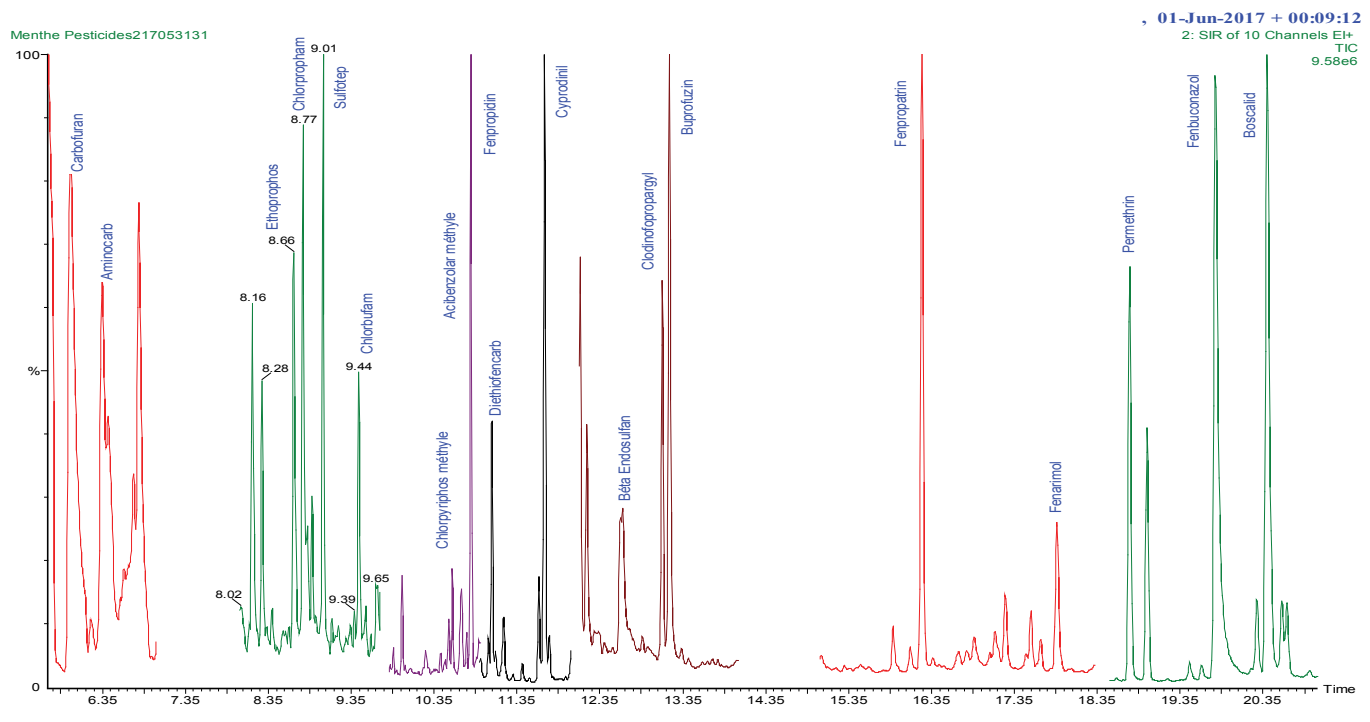

Figure 1: Chromatogram of pesticides in the calibration range.
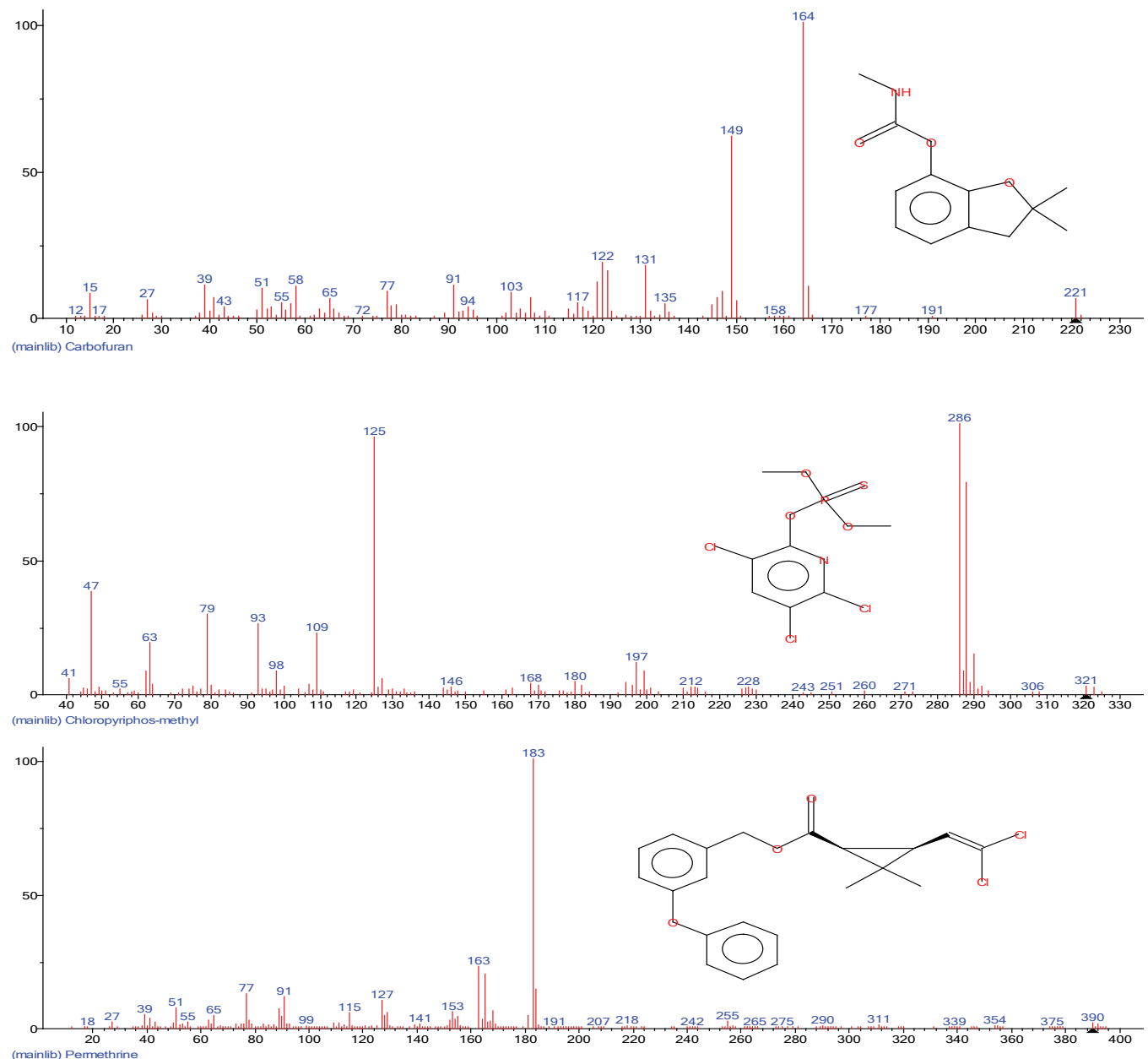

Figure 2: Example of mass spectra of pesticides in the calibration range. 
Citation: Jbilou M, Laarej K, Alami R, Bouklouze A, Cherrah Y, et al. (2018) Determination of Pesticide Residues by GC-MS in Commercialized Mint Samples. J Environ Anal Toxicol 8: 572. doi: 10.4172/2161-0525.1000572

Page 5 of 7

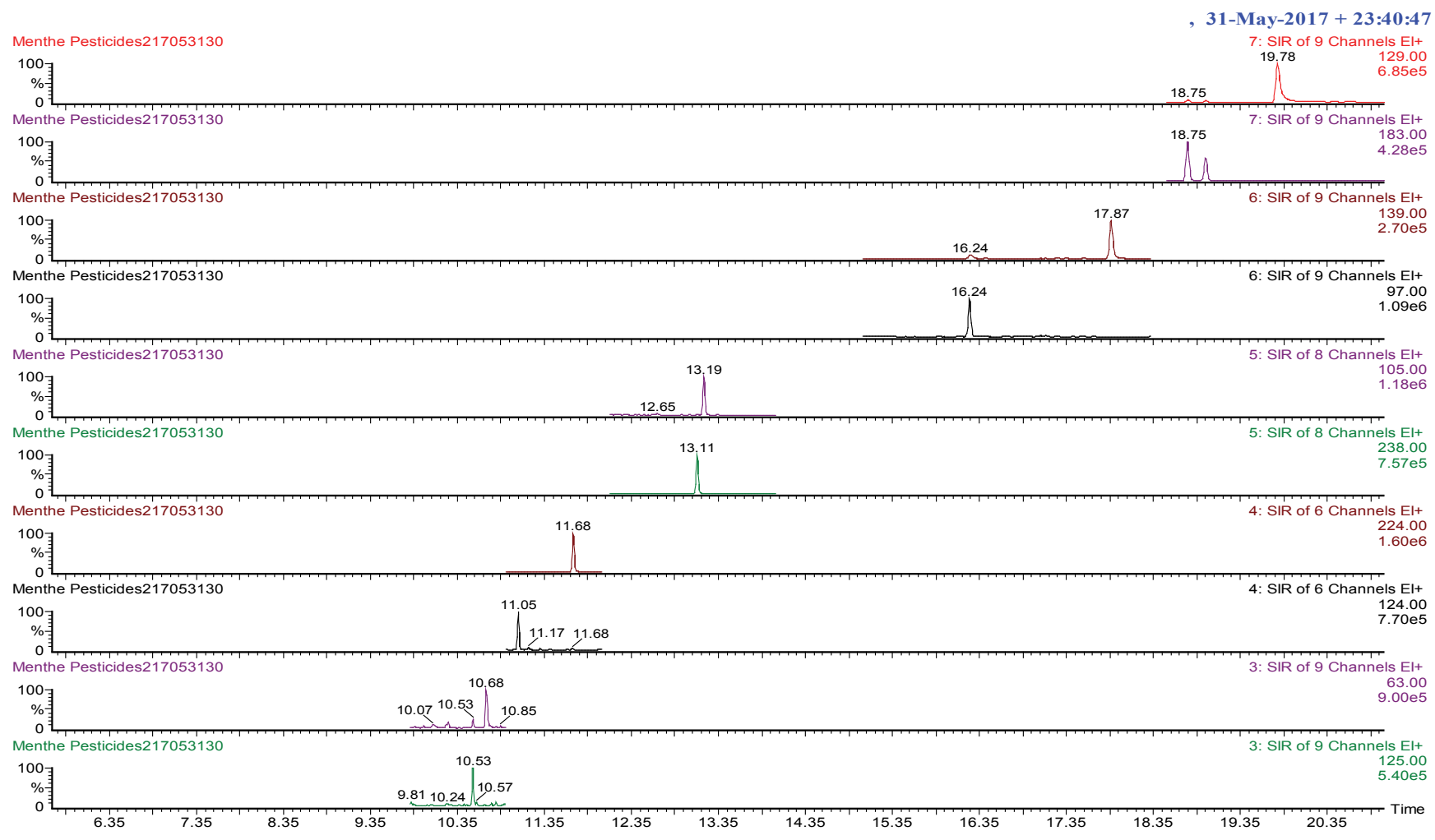

Figure 3: Example of choice of mass peaks for the dosing method.

Menthe Pesticides217053101

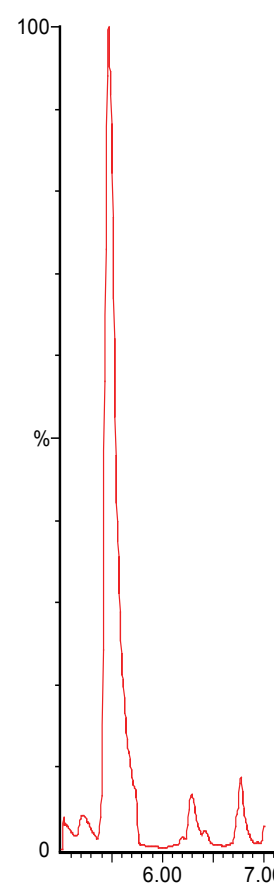

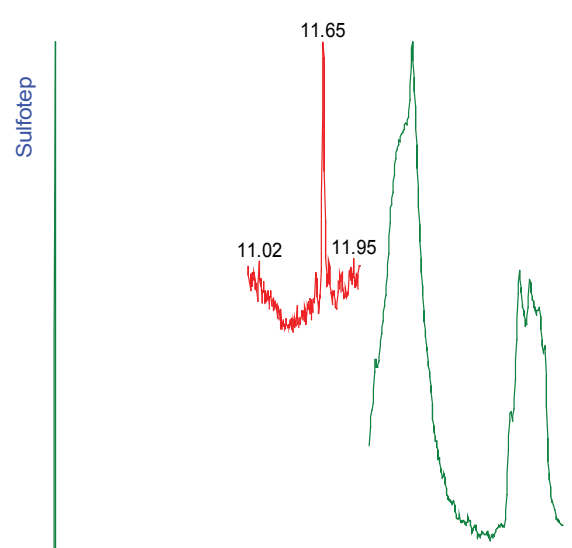

, 31-May-2017 + 09:53:52

4: SIR of 6 Channels El+

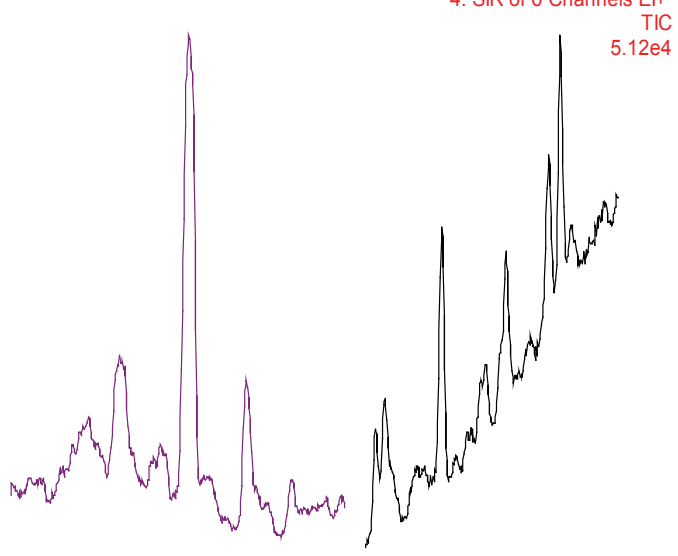


Citation: Jbilou M, Laarej K, Alami R, Bouklouze A, Cherrah Y, et al. (2018) Determination of Pesticide Residues by GC-MS in Commercialized Mint Samples. J Environ Anal Toxicol 8: 572. doi: 10.4172/2161-0525.1000572
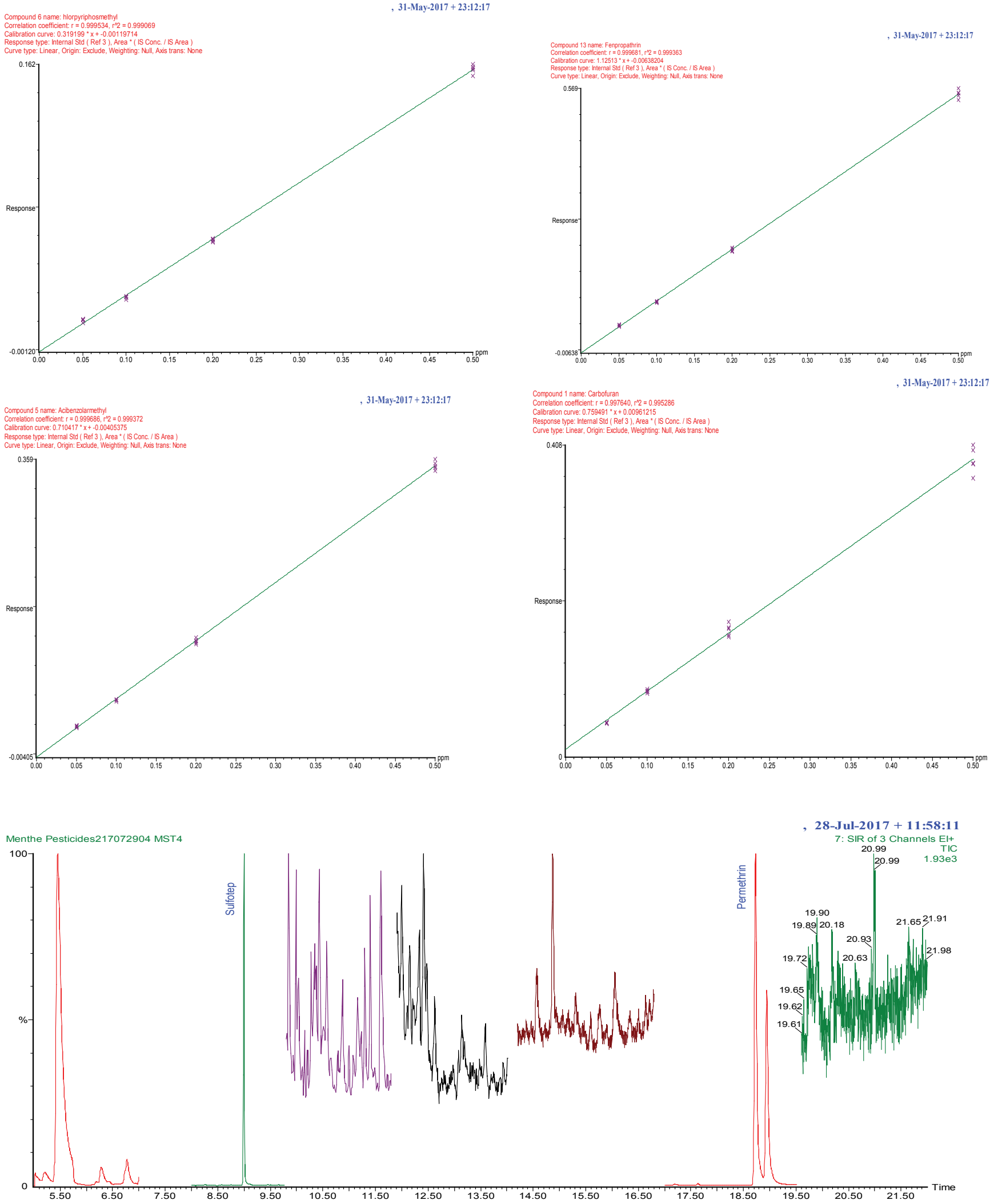

Figure 5: Chromatogram of a mint extract (MST4) contaminated with permethrin 
Citation: Jbilou M, Laarej K, Alami R, Bouklouze A, Cherrah Y, et al. (2018) Determination of Pesticide Residues by GC-MS in Commercialized Mint Samples. J Environ Anal Toxicol 8: 572. doi: 10.4172/2161-0525.1000572

\section{References}

1. Khanuja SP, Shasany AK, Srivastava A, Kumar S (2000) Assessment of genetic relationships in Mentha species. Euphytica 111: 121-125.

2. Chadefaud M (1960) Les végétaux non vasculaires (Cryptogamie). Traite de botanique systematique. Tome, pp: 613-616.

3. Tazi A (1986) Revue de l'Académie du Royaume du Maroc 3: 29.

4. Eddaya T, Boughdad A, Becker L, Chaimbault P, Zaïd A (2010) Use and risks of pesticides in sanitary protection of spearmint in south-central Morocco.

5. Edwards J, Bienvenu FE (2000) Corp Protection 19: 5.

6. Elfadl A, Skiredj A, Elattir H (2002) Bulletin de transfer et de Technologie de l'Agriculture 97: 5.

7. Ezzahiri B, Bouhache M, Mihi M, Erraki I (2004) Index phytosanitaire du Maroc. Association marocaine de protection des plantes (AMPP). Rabat Instituts Maroc, p: 257.

8. Ezzahiri B, Bouhache M, Mihi M (2011) Index phytosanitaire Maroc (Physotanitary index Morocco). Association Marocaine de Protection de Plantes, Rabat, p: 304.

9. Pimentel D, Acquay HA, Biltomen M, Rice P, Silva M, et al. (1992) Bioscience 42: 11.
10. Samuel O, Saint-Laurent $L$ (2001) Institut de recherches en santé et en sécurité de travail du Québec, p: 92.

11. Deguine J, Ferron P, Russell D (2008) Protection des cultures: De l'agrochimie à l'agroécologie. Quoe.

12. Abhilash PC, Singab N (2009) Journal of Hazardous Matériels 165: 12.

13. FAO/OMS (2004) Note commune à l'intention des medias OMS/FAO 19: 3.

14. Mmi N, Soulaymani RA, Bencheikh SR (2010) Toxicologie Maroc. Publication Officielle du Centre Antipoison du Maroc 4: 3.

15. Belomaria M, Omar Nabil A, Ahami T, Aboussaleh Y, Elbouhali B, et al. (2007) 14: 6 .

16. De Cormis L (1994) Qualité de l'environnement, pesticides et pratiques agricoles. Études et Recherches sur les Systèmes Agraires et le Développement, pp: 65-72.

17. EACE (2007) Etablissement autonome de contrôle et de coordination des exportations. Actualité Export 21: 19.

18. RASFF (2009) The rapid alert System for Food and Feed. Annual Report, p: 76.

19. USEPA (2009) Reregistration Eligibility Decision (RED) for Permethrin. Office of Prevention. Pesticides and Toxic Substances. 